\title{
Crystal structures of Lymnaea stagnalis AChBP in complex with neonicotinoid insecticides imidacloprid and clothianidin
}

\author{
Makoto Ihara $\cdot$ Toshihide Okajima $\cdot$ Atsuko Yamashita $\cdot$ Takuma Oda $\cdot$ Koichi Hirata \\ Hisashi Nishiwaki $\cdot$ Takako Morimoto $\cdot$ Miki Akamatsu $\cdot$ Yuji Ashikawa Shun'ichi Kuroda \\ Ryosuke Mega $\cdot$ Seiki Kuramitsu $\cdot$ David B. Sattelle $\cdot$ Kazuhiko Matsuda
}

Received: 20 February 2008/ Accepted: 29 February 2008/Published online: 13 March 2008

(C) The Author(s) 2008

\begin{abstract}
Neonicotinoid insecticides, which act on nicotinic acetylcholine receptors (nAChRs) in a variety of ways, have extremely low mammalian toxicity, yet the molecular basis of such actions is poorly understood. To elucidate the molecular basis for nAChR-neonicotinoid interactions, a surrogate protein, acetylcholine binding protein from Lymnaea stagnalis (Ls-AChBP) was
\end{abstract}

Makoto Ihara, Toshihide Okajima, Atsuko Yamashita contributed equally to this study.

M. Ihara · A. Yamashita $\cdot$ Y. Ashikawa

RIKEN SPring-8 Center, 1-1-1 Kouto, Sayo,

Hyogo 679-5148, Japan

T. Okajima $\cdot$ S. Kuroda

Department of Structural Molecular Biology,

Institute of Scientific and Industrial Research, Osaka University,

Ibaraki, Osaka 567-0047, Japan

T. Oda $\cdot$ K. Hirata $\cdot$ H. Nishiwaki $\cdot$ K. Matsuda $(\bowtie)$

Department of Applied Biological Chemistry,

School of Agriculture, Kinki University,

3327-204 Nakamachi, Nara 631-8505, Japan

e-mail: kmatsuda@nara.kindai.ac.jp

T. Morimoto $\cdot$ M. Akamatsu

Graduate School of Agriculture, Kyoto University,

Kita-shirakawa, Sakyo-ku, Kyoto 606-8502, Japan

R. Mega $\cdot$ S. Kuramitsu

Graduate School of Science, Osaka University,

1-1 Machikaneyama, Toyonaka, Osaka 560-0043, Japan

D. B. Sattelle

MRC Functional Genetics Unit,

Department of Physiology Anatomy and Genetics,

University of Oxford, South Parks Road,

Oxford OX1 3QX, UK crystallized in complex with neonicotinoid insecticides imidacloprid (IMI) or clothianidin (CTD). The crystal structures suggested that the guanidine moiety of IMI and CTD stacks with Tyr185, while the nitro group of IMI but not of CTD makes a hydrogen bond with Gln55. IMI showed higher binding affinity for $L s$-AChBP than that of $\mathrm{CTD}$, consistent with weaker $\mathrm{CH}-\pi$ interactions in the $L s$-AChBP-CTD complex than in the $L s$-AChBP-IMI complex and the lack of the nitro group-Gln55 hydrogen bond in CTD. Yet, the NH at position 1 of CTD makes a hydrogen bond with the backbone carbonyl of Trp143, offering an explanation for the diverse actions of neonicotinoids on nAChRs.

Keywords Acetylcholine binding protein (Lymnaea stagnalis) · Crystal structures · Neonicotinoids . Nicotinic acetylcholine receptors $\cdot$ Ion channels

\section{Introduction}

Nicotinic acetylcholine receptors (nAChRs) are ligandgated ion channels that mediate fast-acting excitatory cholinergic neurotransmission in vertebrates and invertebrates. Each nAChR molecule consists of five subunits; acetylcholine (ACh) binds at extracellular ligand-binding domain (LBD) at the subunit interfaces, and a central, cation-permeable ion channel opens transiently in response to ACh and agonists (Karlin 2002; Sine and Engel 2006). Each subunit possesses an $\mathrm{N}$-terminal extracellular domain with a conserved di-cysteine loop, four transmembrane regions (TM1-TM4 of which TM2 provides most of the channel-lining residues), and a large intracellular loop between TM3 and TM4 (Karlin 2002). Usually, nAChRs are made up of $\alpha$ and non- $\alpha$ subunits (Fig. 1a), the $\alpha$ 
subunits being defined by adjacent cysteines in loop $\mathrm{C}$ of LBD. The ACh binding site is located at the LBD interfaces and formed by loops A, B and C of the $\alpha$ subunit and loops $\mathrm{D}, \mathrm{E}$ and $\mathrm{F}$ which are normally located in non- $\alpha$ subunit (Corringer et al. 2000; Karlin 2002; Lindstrom 2003). However, $\alpha 7, \alpha 8$ and $\alpha 9$ subunits can form functional homo-pentamers (Couturier et al. 1990; Elgoyhen et al. 1994; Gerzanich et al. 1994) (Fig. 1a), whereas $\alpha 9$ and $\alpha 10$ subunits form $\alpha$ hetero pentamers (Elgoyhen et al. 2001). When only $\alpha$ subunits are present, they donate not only loops A-C, but also loops D-F.

In mammals, nAChRs play central roles in neuromuscular and inter-neuronal cholinergic neurotransmission. Mutations in muscle nAChR subunits account for many cases of congenital myasthenia syndrome (Engel et al. 2003) and also multiple pterygium (Morgan et al. 2006), whereas mutations in neuronal $\mathrm{nAChR}$ subunits $(\alpha 4, \beta 2)$ can produce epilepsies (Aridon et al. 2006; Steinlein 2004). It has also been shown that cholinergic neurotransmission is reduced in Alzheimer's (Marutle et al. 1999) and Parkinson's diseases as well as in schizophrenia (Woodruff-Pak and Gould 2002). Further, in some cases of Alzheimer's disease, loss of nAChRs has been reported (Court et al. 2001). Thus there is a growing interest in nAChRs as potential drug targets (Arneric et al. 2007; Dani and Bertrand 2007).

In the insect nervous system, where $\mathrm{ACh}$ is the primary excitatory neurotransmitter, nAChRs are present at densities comparable to those in the electric organ of the electric fish, Electrophorus electricus (Sattelle 1980), and several classes of insecticides (cartap, bensultap, thiocyclam, spinosad and neonicotinoids) target insect nAChRs (Narahashi 2000; Raymond-Delpech et al. 2005; Millar and Denholm 2007). Of these, neonicotinoids (Fig. 1a) are increasingly used not only for controlling crop pests worldwide, but also for animal health application such as flea and louse controls. Imidacloprid (IMI; Fig. 1b), the first insecticide with billion dollars per annum sales, is a partial agonist of native (Deglise et al. 2002; Ihara et al. 2006; Tan et al. 2007) as well as of recombinant (Ihara et al. 2003) nAChRs expressed in Xenopus laevis oocytes. On the other hand, clothianidin (CTD; Fig. 1b) and its analog evoke supra-maximal responses (with reference to ACh responses) not only in the Drosophila D $\alpha 2 /$ chicken $\beta 2$ hybrid nAChRs (Ihara et al. 2004) expressed in Xenopus oocytes, but also in native Drosophila central cholinergic neurons (Brown et al. 2006). Single channel recording has shown that a CTD analog induces the opening of the Drosophila nAChR channels at the largest conductance state more frequently than $\mathrm{ACh}$, offering a possible explanation for its super-agonist action (Brown et al. 2006). Contrasting with these actions, some neonicotinoids (Ihara et al. 2006; Salgado and Saar 2004), and bis-neonicotinoids containing two neonicotinoid units
Fig. 1 Nicotinic acetylcholine receptors (nAChRs) and the acetylcholine binding protein (AChBP). a Schematic representation of neuronal nicotinic acetylcholine receptors and acetylcholine binding protein. b Chemical structures of natural nicotinic ligands and neonicotinoids [imidacloprid (IMI) and clothianidin (CTD)] used in this study. c Multiple sequence alignment of AChBP with the ligand binding domain of nAChR subunits. Lymnaea stagnalis AChBP (Ls$\mathrm{AChBP}$ ) and N-terminus LBD sequences of insect (species names are colored magenta) and vertebrate (species names are colored black) nAChRs are aligned using ClustalW2 program (Larkin et al. 2007) with default parameters and the details are manually adjusted. Secondary structure elements from the $L s$-AchBP-IMI complex are indicated above the multiple alignments. Amino acids involved in the interactions with neonicotinoids are highlighted in bold with yellow and cyan backgrounds in the principal (+)- and complementary (-)sides, respectively. Amino acid residue number from methionine for each protein was indicated at the top of each sequence

joined together by an alkyl chain (Ihara et al. 2007a), antagonize the acetylcholine-induced responses of native insect neurons.

Neonicotinoids show higher affinity for insect nAChRs, accounting, at least in part, for their selective toxicity to insects over vertebrates (Matsuda et al. 2001, 2005; Tomizawa and Casida 2005). Our studies using sitedirected mutagenesis combined with two-electrode voltage-clamp electrophysiology have shown that the $\mathrm{X}$ residue in the YXCC motif of loop $\mathrm{C}$ (Shimomura et al. 2004), the region upstream of loop B (Shimomura et al. 2005) and basic residues in loop D (Shimomura et al. 2002, 2003, 2006) contribute to the high neonicotinoid sensitivity of insect nAChRs (see Fig. 1c for loop positions).

The acetylcholine binding protein (AChBP) from snail, Lymnaea stagnalis (Ls-AChBP) was discovered in glial cells as a water soluble protein modulating synaptic ACh concentration (Smit et al. 2001), and the X-ray crystal structure of the protein was described at the same time (Brejc et al. 2001). Subsequently, X-ray crystal structures of Ls-AChBP homologs from Aplysia californica (AcAChBP) (Bourne et al. 2005) and Bulinus truncatus (BtAChBP) (Celie et al. 2005b) were reported. Both $L s$ - and $A c$-AChBPs show similarities to the extracellular domain of neuronal $\alpha 7 \mathrm{nAChRs}$ and form homopentamers in solution (Smit et al. 2001). Notably, all the six regions (loops A-F) that make up the ligand binding site are conserved in AChBPs. Thus AChBPs are considered as surrogates of the LBD in nAChRs and therefore have been employed to elucidate the mechanism for interactions with low molecular weight ligands as well as peptide toxin antagonists (Bourne et al. 2005; Celie et al. 2004, 2005; Dutertre et al. 2007; Hansen et al. 2005; Hansen and Taylor 2007; Ulens et al. 2006). Employing the crystal structures of AChBPs, we have previously modeled LBDs in complex with IMI to show that basic residues in loop D may interact 
nAChRs

Hetero pentamer e.g. $\alpha 4 \beta 2$

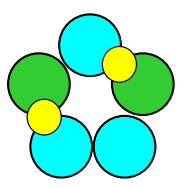

$\alpha$ Subunits
Homo pentarmer e.g. $\alpha 7$

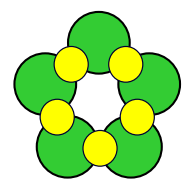

Non- $\alpha$ Subunits
AChBP

Homo pentarmer

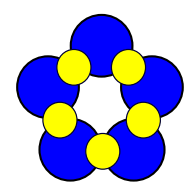

Ligands b

Natural ligands<smiles>CC(=O)OCC[N+](C)(C)C</smiles>

Acetylcholine

Neonicotinoids<smiles>O=[N+]([O-])/N=C1\NCCN1Cc1ccc(Cl)nc1</smiles>

Imidacloprid (IMI)<smiles>C[NH+]1CCCC1c1cccnc1</smiles>

Nicotine
C

Lymnaea stagnalis AChBP Drosophila melanogaster $\alpha 1$ Drosophila melanogaster $\alpha 2$ Drosophila melanogaster $\alpha^{3}$ Gallus gallus $\alpha 4$ Gallus gallus $\alpha 7$ Homo sapiens $\alpha 4$ Homo sapiens $\alpha 7$ Anopheles gambiae $\beta 1$ Drosophila melanogaster $\beta 1$ Drosophila melanogaster $\beta 2$ Locusta migratoria $\beta$ Gallus gallus $\beta 2$ Gallus gallus $\beta 4$ Homo sapiens $\beta 2$ Homo sapiens $\beta 4$
Lymnaea stagnalis AChBP Drosophila melanogaster $\alpha 1$ Drosophila melanogaster $\alpha 2$ Drosophila melanogaster $\alpha 3$ Gallus gallus $\alpha 4$ Gallus gallus $\alpha 7$ Homo sapiens $\alpha 4$ Homo sapiens $\alpha 7$ Anopheles gambiae $\beta 1$ Drosophila melanogaster $\beta 1$ Drosophila melanogaster $\beta 2$ Locusta migratoria $\beta$ Gallus gallus $\beta 2$ Gallus gallus $\beta 4$ Homo sapiens $\beta 2$ Homo sapiens $\beta 4$
Lymnaea stagnalis AChBP Drosophila melanogaster $\alpha 1$ Drosophila melanogaster $\alpha 2$ Drosophila melanogaster $\alpha 3$ Gallus gallus $\alpha 4$ Gallus gallus $\alpha 7$ Homo sapiens $\alpha 4$ Homo sapiens $\alpha 7$ Anopheles gambiae $\beta 1$ Drosophila melanogaster $\beta 1$ Drosophila melanogaster $\beta 2$ Locusta migratoria $\beta$ Gallus gallus $\beta 2$ Gallus gallus $\beta 4$ Homo sapiens $\beta 2$ Homo sapiens $\beta 4$

$\alpha 1$

$$
1 \text { elecelecee }
$$

LDRADILYNIROTS (22) NPDAKRIYDDIISN .

(42) NPDAKRIYDDIISN

(23) NPDAKRLYDDLLSN

(29) AHAEERLLKKLFSG

(23) GEFORKLYKELLKN

(17) AHAEERLIKKLFSG .

(24) GEFQRKLYKELVKN

24) SEDEERLVRDLFRG.

(25) SEDEERLVRDLFRG

(1) NPDTKRLYDDLLSN .

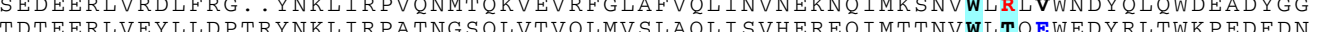
25) ADAEEKLMNHLLSPDRYNKLIRPAVNSSQLVS I ELQVSLAQL I SVNEREQIMTTNVWLNQEWIDYRLAWKPSDYEG

28) TDTEERLVEHLLDPSRYNKLIRPATNGSELVTVQLMVS LAQLISVHEREQIMTTNVWLTQEWEDYRLTWKPEEFDN

(26) ANAEEKLMDDLLNKTRYNNLIRPATSSSQLISIKLQLSLAQLISVNEREQIMTTNVWLKQEWTDYRLTWNSSRYEG

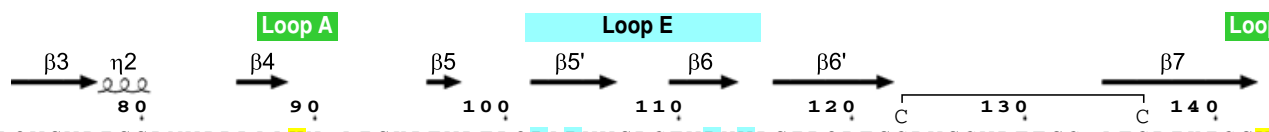

. DQVSVPISSLWVPDLAAYN. AISKPEVLTPQLARVVSDGEVLYMPSIRQRFSCDVSGVDTESG. ATCRIKIGSWTHH VDTLHVPSEH IWH PD IVLYNNAD GNYEVT IMTKA I LHHTGKVVWK P PA IYK SFCE I DVEYF PFDEOTCFMKFGSWTYD

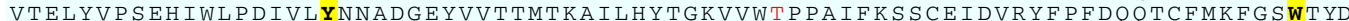
VEMLHVPSDH IWRPDIVLYNNADGNFEVTLATKATLNYTGRVEWRPPA IYKSSCEIDVEYFPFDEOTCVMKFGSWTYD VTSIR P VKNVRFPDGLIWKPDILIYNSADERFDATF TNVLVNSSGHCOYLPPGIFKSSCYIDVRWFPFDVOKCNLKFGSWTYG VTSIRIPSE VKTVRFPDGQIWK PDILLYNSADERFDATFHTNVLVNSSGHCOYLPPGIFKSSCYIDVRWFPFDVOHCKLKFGSWSYG VKTVRFPDGQIWK PDI LLYNSADERFDATFH TNVLVNSSGHCQYLPPG IFKSSCY IDVRWFP DVQHCKLKFGSWSYG
IGVLRLPPDKVWKPDIVLFNNADGNYEVRYKSNVLIYPNGEVLWVPPAIYQSSCTIDVTYFP DQQTCIMKFGSWTFN I GVLRLPPDKVWKPDIVLFNNADGNYEVRYKS NVIIYPTGEVLWVPPAIYQSSCTIDVTYFPFDQQTCIMKFGSWTFN VEQ LYVPSEH I WVPD I VLYNNWD GNYEVTLMTKA TLKYTGEVFWEPPA I YKSS CEMNVEYFPYDEQ I C F K F GSWTYN IGVLRLPPDKVWKPDIVLFNNADGNYEVRYKSNVLIYPNGEVLWVP PAIYQSSCTIDVTYFPFDQQTCIMKFGSWTFN MKKVRLPSKHIWLPDVVLYNNADGMYEVSFYSNAVISYDGS IFWLPPAIYKSACKIEVKHFPFDQONCTMKFRSWTYD INMLRIPAKHIWLPDIVLYNNADGTYEVS LYTNAIVQNNGS I RWLPPA IYKSACKIEVKHFPFDQQNCTLKFRSWTYD MKKVRI PSKHIWL PDVVIYNNADGMYEVSFYSNAVVSYDGSIFWLP A IYKSACKIFVKHFPFDQONCTMKERSWTYD VNILRI PAKRIWLPDIVLYNNADGTYEVSVYTNLIVRSNGSVLWLPPAIYKSACKIEVKYFPFDQNCTLKFRSWTYD

Loop F

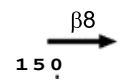
SREISVDPTTE. . GYMVDLRHLKQTAD. SDN I EVGIDLODYYIS. VEWDIMRVPAVRNEKFYSCCEEPYLDIVFNLTLRRKTLFYTVNI GDQIDLKHISQKNDKDNKVEIGIDLREYYPS. VEWDILGVPAERHEKYYPCCAEPYPDIFFNITLRRKTLFYTVNL GFOVDLRHIDELNG. TNVVEVGVDLSEFYTS. VEWDILEVPAVRNEKFYTCCDEPYLDITFNITMRRKTLFYTVNL KAK I DLVSMH........... SHVDOLDYWES. GEWVIINAVGNYNSKKYECCTEIYPDITYSFIIRRLPLFYTINL

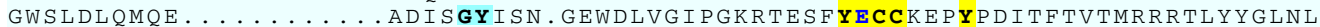
KAKIDLVNMH ..............................

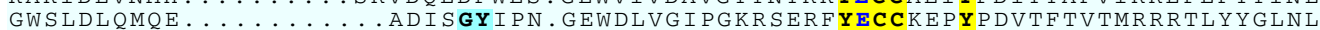
GDQVSLALYNN ........ KNFVDLSDYWKS. GTWDIIEVPAYLNVYEGN... PTETDITFYIIIRKTLFYTVNL GDQVSLALYNN.........KNFVDLS DYWKS. GTWDIIEVPAYLNVYEGDSNHPTETDITFYIIIRRKTLFYTVNL GAQVDLKHLDQI PG. SNLVQVG I LTEFYLS. VEWDILEVPATKNEEYYPDTLEPF D ITFKLTMRRKTLFYTVNL GDQVSLALYNN.......... KTFVDLS DYWKS. GTWDIIEVPAYLNIYEGN. . HPTETDITFYIIIRRKTLFYTVNL RTEIDLVLKS.......... EVASLDDFTPS. GEWDIVALPGRRNENPDDST... YVDITYDFIIRRKPLFYTINL

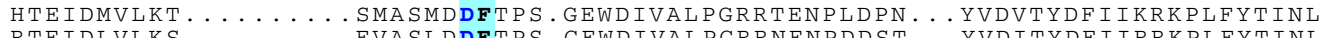
HTEIDMVLMT.......... PTASMDDFTPS. GEWDIVALPGRRTVNPQDPS. . YVDVTYDFIIKRKPLFYTINL 
electrostatically with the nitro group of neonicotinoids (Shimomura et al. 2006). Yet, details of neonicotinoidnAChR interactions are poorly understood. Therefore, we have crystallized the $L s$-AChBP in complex with two commercial neonicotinoids, IMI and CTD.

\section{Materials and methods}

Materials

Lymnaea stagnalis derived from the stocks of Vrije Universeit (Amsterdam) was provided from Professor Sakakibara at Tokai University. IMI and CTD were gifts from BayerCropscience Co. in Japan. 1-(6-Bromopyridylmethyl)-2-nitroiminoimidazolidine (bromine-substituted imidacloprid; Br-IMI) and $\mathrm{N}$-(2bromo-thiazol-5-ylmethyl)- $N^{\prime}$-methyl- $N^{\prime \prime}$-nitroguanidine (bromine-substituted clothianidin; Br-CTD) were synthesized according to the published methods (Maienfisch et al. 2000; Nishiwaki et al. 2000).

\section{Protein preparation}

The cDNA of $L s$-AChBP was amplified by RT-PCR from L. stagnalis and was cloned into the pPICZ $\alpha$ B vector (Invitrogen) at the Pst I site, with an L1A mutation introduced to facilitate cloning. The $L s$-AChBPs were expressed in yeast, Pichia pastris X-33 using EasySelect Pichia Expression Kit (Invitrogen). Secreted proteins were purified with Q-Sepharose column (GE Healthcare) immediately following concentration and buffer-exchange using Vivaflow200 (Zartorius), and then treated with $50 \mathrm{U} / \mathrm{mg}$ protein of peptide- $N$-glycosidase F (Wako Pure Chemical Industries) at $37^{\circ} \mathrm{C}$ for $24 \mathrm{~h}$ to remove the glycosyl-chain at Asn67. The protein samples were subsequently purified with Mono Q and Superdex 200 columns (GE Healthcare). Purified proteins were confirmed to be the samples of interest by $\mathrm{N}$-terminal sequencing and mass spectrometry. Purified proteins were buffer-exchanged against $20 \mathrm{mM}$ Tris- $\mathrm{HCl}$ buffer with $0.02 \% \mathrm{NaN}_{3}(\mathrm{pH}$ 8.0).

Evaluation of equilibrium binding of neonicotinoids

The equilibrium binding of neonicotinoids with $L s$-AChBP was determined by quenching of intrinsic tryptophan fluorescence. $L s-A C h B P$ at $600 \mathrm{nM}$ in binding site concentration in $20 \mathrm{mM}$ Tris- $\mathrm{HCl}$ buffer with $0.02 \% \mathrm{NaN}_{3}$ ( $\mathrm{pH}$ 8.0) was incubated with each ligand at various concentrations on a 96-well plate. $L s-\mathrm{AChBP}$ was excited at $280 \mathrm{~nm}$, and emission intensity was recorded at $342 \mathrm{~nm}$ using Varioskan microplate reader (Thermo Fisher
Scientific) at room temperature. Data were fitted by nonlinear regression according to the following equation using Prism Software version 4.03 (GraphPad Software):

$$
\begin{aligned}
& \frac{\Delta F}{F_{0}}=\frac{\Delta F_{\max }}{F_{0}} \\
& \cdot \frac{K_{\mathrm{d}}+[\mathrm{X}]+[\text { Protein }]-\sqrt{\left(K_{\mathrm{d}}+[\mathrm{X}]+[\text { Protein }]\right)^{2}-4 \cdot[\mathrm{X}] \cdot[\text { Protein }]}}{2 \cdot[\text { Protein }]},
\end{aligned}
$$

where $\Delta F$ and $\Delta F_{\max }$ represent quenching of fluorescence at a ligand concentration $\mathrm{X}$ and maximum quenching of fluorescence at saturation, respectively. $F_{0}$ and [Protein] are fluorescence measured in the absence of ligands and the concentration of $L s$-AChBP, respectively.

Crystallization and X-ray data collection

Purified $L s$-AChBPs $(6.0 \mathrm{mg} / \mathrm{mL})$ were incubated with $0.5 \mathrm{mM}$ neonicotinoids at $4{ }^{\circ} \mathrm{C}$ for $1 \mathrm{~h}$ prior to crystallization. $L s$-AChBP-neonicotinoid complex crystals were obtained by vapor diffusion method at $20^{\circ} \mathrm{C}$ with $1: 1$ ratio of protein to reservoir solution containing $0.2 \mathrm{M} \mathrm{Na}$ citrate $\mathrm{pH} 5.7,15-22 \%$ PEG3350 and about $0.5 \mathrm{mM}$ of either IMI, CTD, Br-IMI or Br-CTD. The crystals were flash-cooled in liquid nitrogen after soaking into the cryoprotectant solutions containing $0.2 \mathrm{M} \mathrm{Na}$ citrate $\mathrm{pH}$ 5.7, 25\% PEG3350, 20\% glycerol and about $0.5 \mathrm{mM}$ of each neonicotinoid. X-ray diffraction data sets were collected at $90 \mathrm{~K}$ using either Bruker AXS DIP6040 detector at BL44XU (Yoshimura et al. 2007) or ADSC QUANTUM 210 detector at BL44B2 (Adachi et al. 2001) beamlines in SPring- 8 , and processed with Mosflm (Leslie 1992) or HKL2000 (Otwinowski and Minor 1997). In order to identify the positions of the sulfur atom at the thiazole ring of CTD as well as the bromine atom of Br-IMI and Br-CTD, anomalous data from the crystals complexed with these neonicotinoids were collected at wavelength of $1.75 \AA$ and $0.919 \AA$ (Table 1), respectively.

Structure determination and refinement

The structure of the IMI complex was solved by molecular replacement with Phaser (McCoy 2007) using the coordinates of an $L s$-AChBP in complex with nicotine (PDB entry: 1UW6) (Celie et al. 2004) as a search model. Subsequently, the refined coordinates of the IMI complex were used to solve the structure of the CTD complex. Refinements and manual model building were performed with CNS version 1.2 (Brünger et al. 1998) and Coot (Emsley and Cowtan 2004), respectively. The non-crystallographic-symmetry restraints between the 
Table 1 X-ray diffraction data collection and refinement statistics for $L s$-AChBP-neonicotinoid complexes

\begin{tabular}{|c|c|c|c|c|c|}
\hline & IMI & CTD & Br-IMI & Br-CTD & $\mathrm{CTD}(\mathrm{S} \text { ano })^{\mathrm{a}}$ \\
\hline \multicolumn{6}{|l|}{ Data collection } \\
\hline Beamline $^{\mathrm{b}}$ & BL44XU & BL44B2 & BL44B2 & BL44B2 & BL44B2 \\
\hline Wavelength $(\AA)$ & 0.900 & 0.919 & 0.919 & 0.919 & 1.75 \\
\hline Space group & $P 6_{5}$ & $P 6_{5}$ & $P 6_{5}$ & $P 6_{5}$ & $P 6_{5}$ \\
\hline Cell dimensions $a, c(\AA)$ & $75.0,351.0$ & $74.6,351.0$ & $74.8,350.9$ & $74.5,351.2$ & $74.6,351.3$ \\
\hline Resolution $(\AA)$ & $15.8-2.56$ & $50.0-2.70$ & $50.0-2.70$ & $50.0-2.90$ & $50.0-2.90$ \\
\hline$R_{\mathrm{sym}}(\%)^{\mathrm{c}, \mathrm{d}}$ & $8.0(41.3)$ & $8.5(38.9)$ & $9.7(34.1)$ & $11.8(34.1)$ & $8.7(39.5)$ \\
\hline$I / \sigma^{\mathrm{c}}$ & $8.1(1.7)$ & $20.7(4.0)$ & $47.0(10.7)$ & $45.5(10.9)$ & $60.8(9.32)$ \\
\hline Completeness $(\%)^{\mathrm{c}}$ & $94.8(96.7)$ & $100(100)$ & $100(100)$ & $100(100)$ & $99.5(96.2)$ \\
\hline Redundancy $^{c}$ & $2.6(2.6)$ & $5.7(5.7)$ & $23.0(23.3)$ & $22.5(23.2)$ & $21.6(20.5)$ \\
\hline \multicolumn{6}{|l|}{ Refinement } \\
\hline Resolution $(\AA)$ & $15.8-2.58$ & $50.0-2.70$ & & & \\
\hline No. of reflections & 33031 & 30121 & & & \\
\hline$R / R_{\text {free }}(\%)^{\mathrm{e}}$ & $20.3 / 27.7$ & $20.2 / 27.0$ & & & \\
\hline Bond length $(\AA) /$ angles $(\operatorname{deg})^{f}$ & $0.008 / 1.3$ & $0.008 / 1.3$ & & & \\
\hline Average B factor & 41.8 & 41.6 & & & \\
\hline PDB accession code ${ }^{g}$ & $2 \mathrm{ZJU}$ & $2 \mathrm{ZJV}$ & & & \\
\hline
\end{tabular}

See text for abbreviations of the neonicotinoid names

${ }^{\text {a }}$ Data set for detection of anomalous peaks at sulfur atoms

b All data sets were collected at SPring-8

c Values in parentheses refer to data in the highest resolution shells

${ }^{\mathrm{d}} R_{\text {sym }}=\Sigma|I-\langle I\rangle| / \Sigma I$, where $I$ is the observed intensity and $\langle I\rangle$ is the average intensity from multiple observations of the symmetry-related reflections

${ }^{\text {e }} R=\Sigma\left\|F_{\mathrm{o}}|-| F_{\mathrm{c}}\right\| / \Sigma\left|F_{\mathrm{o}}\right| . R_{\text {free }}$ is an $R$ factor of the CNS refinement evaluated for $5 \%$ of reflections that were excluded from the refinement

${ }^{\mathrm{f}} \mathrm{RMS}$ deviations from ideal values were calculated

g The atomic coordinates and structure factors have been deposited in the Protein Data Bank

subunits were initially applied for the refinements and removed at later steps. The details of data collection and refinement statistics are provided in Table 1. Figures are generated by PyMOL (DeLano Scientific LLC), Bobscript (Esnouf 1999) and Raster3D (Merritt and Bacon 1997).

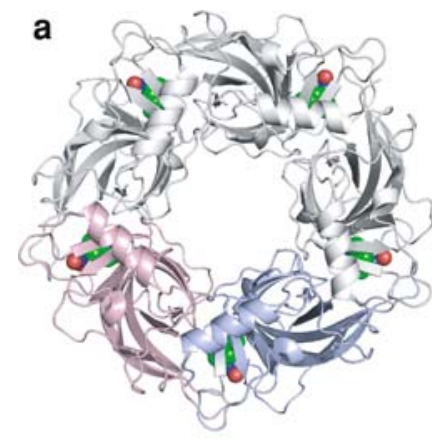

b

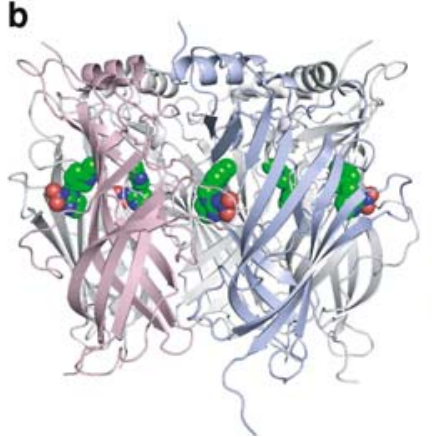

C

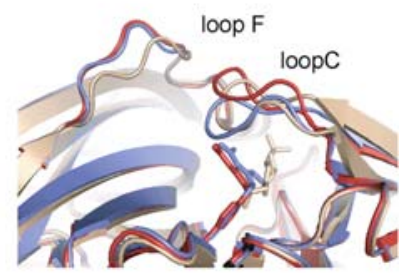

Fig. 2 Overall view of crystal structure of $L s$-AChBP complexed with imidacloprid (IMI). The pentameric structure of $L s$-AChBP is viewed from the top (a) corresponding to an extracellular surface of nAChRs and from the side (b). IMI molecules bound to $L s$-AChBP are shown in space-filling model, whereas carbons, nitrogens and oxygens are colored green, blue and red, respectively. Two subunits, $\mathrm{A}$ and $\mathrm{B}$ chains, are colored by pink and blue, respectively. c The structure of A-B domain boundary of the $L s$-AChBP complexed with IMI (red) is compared with that of the Ls-AChBP complexed with CTD (blue) and the apo form (light brown) complexed with 4-(2hydroxyethyl)-1-piperazineethanesulfonic acid (HEPES) (PDB entry code: 1UX2) (Celie et al. 2004). Ligands are presented by stick models 


\section{Results and discussion}

Structure analysis

In this study, we have crystallized the $L s$-AChBP in complex with IMI and CTD to elucidate the mechanism underpinning their selective and diverse actions on nAChRs. Both complexes were crystallized in the same space group with one pentamer in an asymmetric unit. Ligand-omit and anomalous electron density maps clearly indicated AChBP in the crystals bound neonicotinoids (see Fig. 3a, b). The positions and orientations of the 2chloropyridine ring in IMI and 2-chloro-1,3-thiazole ring in CTD were modeled to satisfy the observation of $\mathrm{Br}$ and $\mathrm{S}$-anomalous peak positions. The $\mathrm{X}$-ray crystal structures of the $L s$-AChBP complexed with IMI and CTD were refined at 2.58 and $2.70 \AA$ resolutions, respectively (Table 1 ).

The neonicotinoid-bound $L s$-AChBPs form the same homopentameric structure (Fig. 2a, b) as those determined for the 4-(2-hydroxyethyl)-1-piperazineethanesulfonic acid (HEPES)-bound apo form (Brejc et al. 2001) and the other ligand-bound forms (Celie et al. 2004, 2005; Hansen et al. 2005; Ulens et al. 2006). Typically, each subunit has a secondary structure composed of an N-terminal 12residue $\alpha$-helix followed by $\beta$-strand-rich parts as shown previously for other $L s$-AChBPs. Root mean square differences (rmsd) of $\mathrm{C} \alpha$ atoms between the IMI- or CTDcomplex and the nicotine-complex (Celie et al. 2004) were observed as 0.975 and $0.758 \AA$, respectively. In two structures determined in the present study, neonicotinoids occupied all five ligand-binding sites that are formed between the two adjacent subunits (Fig. 2a, b). The neonicotinoids occupy broadly the same position as HEPES and (-)-nicotine within the pocket formed by "A-F loop" regions. Although "loops A, B, D and E" are mainly composed of $\beta$-strands and only loops $\mathrm{C}$ and $\mathrm{F}$ have no canonical secondary structure, we use these designations to facilitate comparison with previous studies on nAChRs (Corringer et al. 2000; Matsuda et al. 2001, 2005). The principal side $[(+)$-chain] of the ligand-binding site possesses residues from loops $\mathrm{A}, \mathrm{B}$ and $\mathrm{C}$ which are located in $\alpha$ subunits, whereas the complementary side [(-)-chain] contains loops D, E and F, which are donated by non- $\alpha$ subunits in $\alpha /$ non- $\alpha$ heteropentamers. Overall, the structures of the IMI and CTD complexes were very similar with $\mathrm{C} \alpha \mathrm{rmsd}$ of $0.597 \AA$. However, the loop $\mathrm{C}$ region has a specific conformation in each complex. For example, compared with the IMI complex, loop C of the CTD complex takes a "closed conformation", showing approximately $4 \AA$ shift of the positions of the $\mathrm{C} \alpha$ atoms (Fig. 2c). The variations in loop $\mathrm{C}$ conformation were often observed between different chains within the same
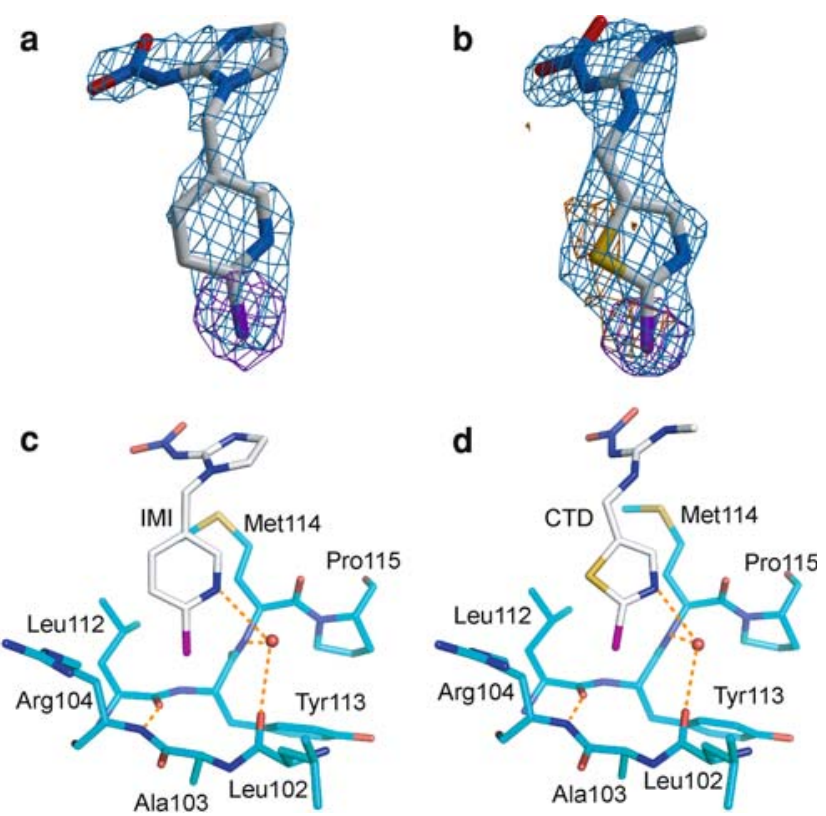

Fig. 3 Electron density maps of bound ligands and their interactions with the loop E region. The annealed $F_{o}-F_{c}$ omit maps (blue) for imidacloprid (IMI) (a) and clothianidin (CTD) (b) bound to the LsAChBP are contoured at $4 \sigma$ and drawn with the final models of the native and non-Br-neonicotinoids. In addition, the anomalous maps of bromine (purple) from the Br-neonicotinoid-complexes and sulfur atoms (yellow) from the native-neonicotinoid-complexes for ligands, which are contoured at 5 and $1.5 \sigma$, respectively, are overlaid. Interactions of the loop E region with pyridine moiety of IMI (c) and thiazole moiety of CTD (d) are shown in the binding site of the LsAChBP. In each ligand and amino acid, chlorine, nitrogen, oxygen and sulfur atoms are colored purple, blue, red and yellow, respectively. The hydrogen bonds are presented by orange broken lines

$L s$-AChBP pentamer in complex with neonicotinoids (e.g. subunits $\mathrm{A}$ and $\mathrm{C}$ of the CTD complex, data not shown). Conformational change in loop $\mathrm{C}$ is evident when comparing structures with the apo form $L s$-AChBP complexed with HEPES (PDB entry code: 1UX2) (Fig. 2c). The Thr155-Asp160 loop region of the (-)-chain upstream of loop $\mathrm{F}$ also indicates a conformational change in the ligand-binding site. These results suggest that induced-fit movement of loop regions is essential for recognition of ligands including neonicotinoids. The detailed binding interactions of neonicotinoids will be considered in relation to their key components, the aromatic ring and the guanidine/related moieties.

Interactions with aromatic rings of insecticides

When complexed with $L s$-AChBP, the pyridine ring of IMI was buried deep in the binding site, interacting with loop $\mathrm{E}$ segments from the (-)-chain (Fig. 3c). Recently, Tomizawa et al. (2008) has reported that two azido-neonicotinoid probes containing the photolabile group in the pyridine ring labeled Tyr164 in loop F of the (-)-chain and Tyr192 in 
loop $\mathrm{C}$ of the (+)-chain in the $L s$-AChBP. However, these two distinct binding modes were not observed in our models, neither in the IMI complex, nor in the CTD complex of the $L s$-AChBP. The nitrogen atom of the pyridine ring forms a hydrogen bond with the amide group of Met114 and the carbonyl group of Leu102 in loop E via a water molecule, resembling the observations for both the Ls-AChBP-nicotine complex (Celie et al. 2004) and $A c$ AChBP-epibatidine complex (Hansen et al. 2005).

The chlorine atom was located in the vicinity of a hydrogen bond bridge between the backbone $\mathrm{C}=\mathrm{O}$ of Leu112 and the backbone amide NH of Arg104. As a result, it made van der Waals contact the peptide backbones of these two amino acids. The aromatic ring of CTD also contacts with the loop E segment in a manner similar to IMI (Fig. 3d). The nitrogen atom of the thiazole ring of CTD, in a similar fashion to the nitrogen atom of the pyridine ring of IMI, formed hydrogen bond with the backbone carbonyl of Leu102 and the backbone amide group of Met114 via water molecule (Fig. 3d).

Nicotine, which is active not only on insect, but also on vertebrate nAChRs, has also been shown to interact with the backbone of loop $\mathrm{E}$ in a similar manner to neonicotinoids (Celie et al. 2004). Therefore interactions with the backbone are insufficient to explain the selective actions of neonicotinoids. On the other hand, Met114 in loop E was located in the vicinity of the nitroimine group (Fig. 3c, d) which plays a key role in selective insect nAChR-neonicotinoid interactions (Ihara et al. 2003). Some insect $\alpha$ subunits possess either basic or hydrogen bondable residues favorable for interactions with the nitro group such as those corresponding to Met114 (Fig. 1c). Hence, if two adjacent $\alpha$ subunits form a ligand-binding site, such residues may contribute to the neonicotinoid sensitivity of insect nAChRs.

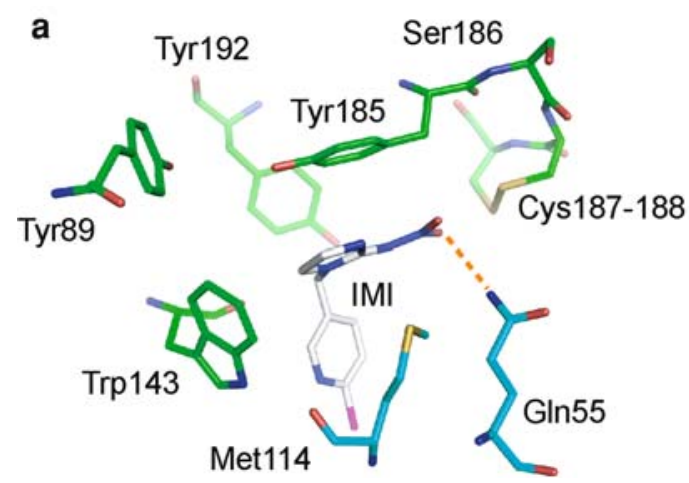

Fig. 4 Imidacloprid (IMI) and clothianidin (CTD) binding to Lymnaea stagnalis $\mathrm{AChBP}(L s-\mathrm{AChBP})$. a IMI- $L s-\mathrm{AChBP}$ complex. b CTD-Ls-AChBP complex. The binding site is located at the interface between two adjacent subunits, as drawn in green for (+)-chains and in cyan for (-)-chain (see text). The subunits EA and CD interfaces are
Interactions with guanidine and related moieties

The crystal structures of the Ls-AChBP bound with nicotine or carbamylcholine (Celie et al. 2004) and Ac-AChBP in the presence of epibatidine (Hansen et al. 2005), as well as quantum chemical calculations (Cashin et al. 2005), suggested that the protonated nitrogen atom in nicotinic agonists undergoes cation- $\pi$ interactions with Trp143 in loop B. In line with this notion, it was earlier demonstrated that the electron-deficient guanidine moiety of neonicotinoids is likely to contact with Trp143 (Matsuda et al. 2005; Tomizawa and Casida 2005). However, the guanidine moiety of IMI and CTD was found to stack with the aromatic ring of Tyr185 in the crystal structures of CTD- as well as IMI- $L s$-AChBP complexes (Fig. 4a, d). Since Tyr185 is conserved throughout vertebrate and invertebrate nAChR $\alpha$ subunits (Fig. 1c), this residue itself is not involved directly in determining the selective interactions with neonicotinoids. Yet the interactions with Tyr185 contribute to the affinity for neonicotinoids. The stacking level for CTD appears to be weaker than that for IMI (Fig. 4a, b). In addition, the stacking interaction resulted in $\mathrm{CH}-\pi$ contacts with Trp143 of the methylene $\left(\mathrm{CH}_{2}-\mathrm{CH}_{2}\right)$ bridge in IMI, which was not seen in CTD, accounting, at least in part, for the higher binding potency of IMI $\left(K_{\mathrm{d}}=1.57 \pm 0.21 \mu \mathrm{M}, n=3\right)$ compared to that of CTD $\left(K_{\mathrm{d}}=7.26 \pm 1.13 \mu \mathrm{M}, n=3\right)$ on the $L s$-AChBP as evaluated by quenching of the protein fluorescence.

Another difference between CTD and IMI is that the former exposes a hydrogen bond donor $\mathrm{NH}$ at position 1 , whereas the latter lacks it. We suggested earlier that this $\mathrm{NH}$ may form a hydrogen bond with the backbone carbonyl of Trp143 in loop B (Ihara et al. 2007b). As suggested, the NH of CTD made a hydrogen bond with the backbone carbonyl of Trp143 from the (+)-chain in the crystal structures of the Ls-AChBP (Fig. 4b), although it was observed at only 2 of 5

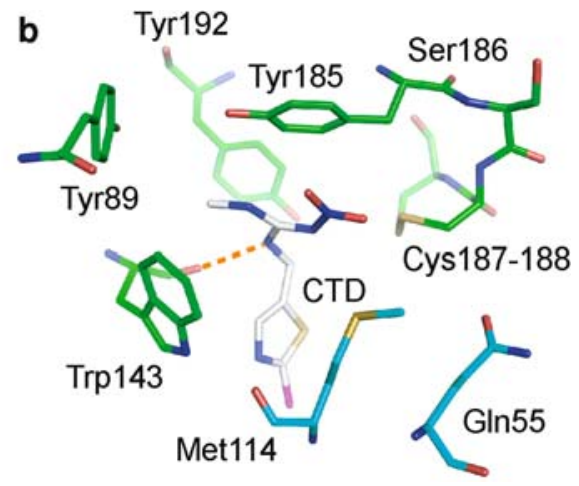

shown for the binding sites for IMI (a) and CTD (b), respectively. Orange broken lines depict hydrogen bonds. In each ligand and amino acid, chlorine, nitrogen, oxygen and sulfur atoms are colored purple, blue, red and yellow, respectively 
interfaces. Such hydrogen bond formation may assist CTD in keeping contact with $\mathrm{nAChRs}$ when large conformational changes occur in LBD to open the central channel (Miyazawa et al. 2003; Unwin 2005), accounting, at least in part, for higher agonist efficacy of CTD compared to IMI and $\mathrm{ACh}$ in certain native and recombinant nAChRs (Brown et al. 2006; Ihara et al. 2004).

Interactions with loop D and selectivity of neonicotinoids

We have previously shown that substitution of a glutamate for the glutamine corresponding to Gln55 of $L s$-AChBP (Fig. 1c) markedly reduced the maximum response to IMI and nitenpyram of the chicken $\alpha 7 \mathrm{nAChR}$, whereas mutation of the same glutamine to arginine enhanced it, slightly shifting the concentration-response curve to the left (lower concentrations). In complete contrast, the same mutation reduced the (-)-nicotine sensitivity of the $\alpha 7$, whereas substitution with a glutamate enhanced it (Shimomura et al. 2002). Therefore, it was postulated that this glutamine residue is likely to be located in close proximity to the nitro group of neonicotinoids, and that marked changes in the $\alpha 7$ response to neonicotinoids as well as (-)-nicotine are the results of electrostatic interactions between the added residues and the nitro group. Consistent with this hypothesis, Gln55 faced the nitro groups of IMI and CTD in the crystal structure of the Ls-AChBP within a hydrogen bondable distance in the AChBP-IMI complex $(<3.3 \AA$ in 2 of 5 interfaces in the crystal structure of the $L s$-AChBP) (Fig. 4). For CTD, however, the distance between the Gln55 and the nitro group was longer than $3.5 \AA$, excluding or minimizing a contribution of hydrogen bonding to the binding potency of CTD.

All vertebrate nAChRs, perhaps apart from those containing either human or rat $\beta 4$ subunit, are likely to show reduced sensitivity to neonicotinoids due to the lack of the basic residues in loop D. The human $\beta 4$ subunit (Fig. 1c), as well as rat $\beta 4$ subunit (sequence not shown), possesses a lysine as residue corresponding to Gln55 of $L s$-AChBP. However, the vertebrate $\beta 4$ subunits possess a glutamate residue as that corresponding to Thr57 in Ls-AChBP which is located in the vicinity of Gln55 (Fig. 5). This glutamate residue is postulated to interfere electrostatically with the neighboring basic residue-neonicotinoid interactions, thereby reducing the neonicotinoid sensitivity of nAChRs containing the $\beta 4$ subunits.

Role of loops $\mathrm{C}$ and $\mathrm{F}$ in their interactions with neonicotinoids

We have found that replacement by glutamate of the proline corresponding to Ser186 in the YXCC motif in

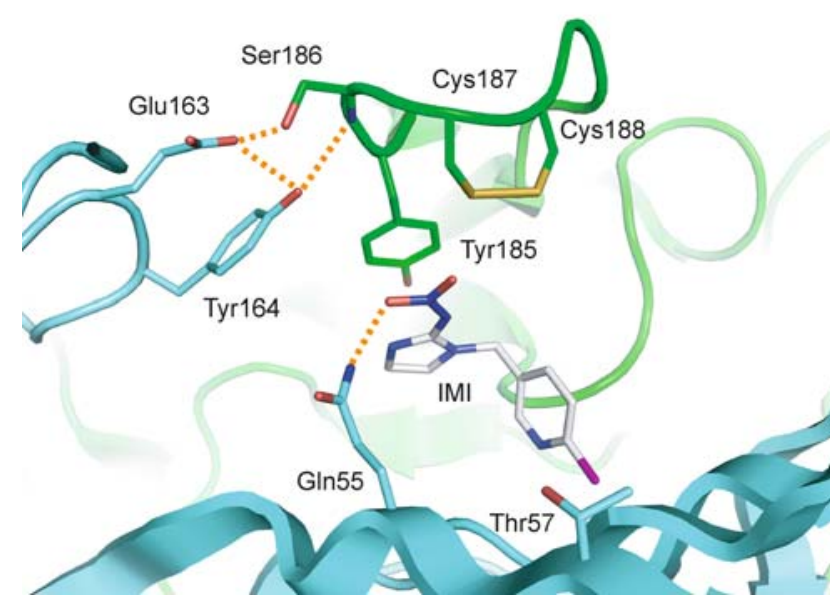

Fig. 5 Interactions between loops C, D and F. IMI-binding site of $L s$ $\mathrm{AChBP}$ is presented by especially focusing on loops C, D and F. The binding site at the interface of the subunits $\mathrm{C}$ and $\mathrm{D}$ is drawn in green for (+)-chains and in cyan for (-)-chain (see text). In each ligand and amino acid, chlorine, nitrogen, oxygen and sulfur atoms are colored purple, blue, red and yellow, respectively. Orange broken lines depict hydrogen bonds

loop C of the Drosophila D $\alpha 2$ subunit reduces the IMI sensitivity of the $\mathrm{D} \alpha 2 \beta 2$ hybrid nAChR, whereas its reverse mutation in the $\alpha 4 \beta 2 \mathrm{nAChR}$ enhanced sensitivity (Shimomura et al. 2004), suggesting a contribution of the loop $\mathrm{C}$ residue to the neonicotinoid sensitivity of nAChRs. However, another view has been proposed in which the serine or threonine residue corresponding to Ser186 from (+)-chain of $L s$-AChBP in loop C of insect nAChRs (see Fig. 1c) forms a hydrogen bond with the nitro group of neonicotinoids, thereby enhancing the binding potency of neonicotinoids (Tomizawa et al. 2007). In the crystal structures of $L s$-AChBP, Ser186 made hydrogen bonds with Glu163 and Tyr164 in loop F of (-)-chain but not with the nitro group of IMI (Fig. 5). This hydrogen bond web, as well as the basic residues in loop $\mathrm{D}$, seems to play an important role in determining the neonicotinoid sensitivity of nAChRs. In most heteromeric vertebrate nAChRs, $\alpha$ subunits possess acidic residues as those corresponding to Ser186 in loop C, resulting in electrostatic repulsion of the acidic residues in loop $\mathrm{F}$ of $\beta$ subunits corresponding to Glu163 in Ls-AChBP (Fig. 1c). On the other hand, insect nAChR $\alpha$ subunits do not possess such an acidic residue in loop C (Fig. 1c). Hence, it is conceivable that amino acids not only from $\alpha$ subunits, but also from non- $\alpha$ subunits of insect nAChRs, contact more effectively with neonicotinoids than those of vertebrate nAChRs. In this context, Tyr164 may also contribute indirectly to the neonicotinoid sensitivity of insect $n A C h R s$ because vertebrate non- $\alpha$ subunits possess phenylalanine residue incapable of assisting the formation of the hydrogen-bond-network at this position. 
In conclusion, we have for the first time elucidated the crystal structures of the $L s$-AChBP in complex with two commercial neonicotinoids IMI and CTD. Met114 in loop $\mathrm{E}$ and Gln55 in Loop D closest to the nitro group in neonicotinoids, suggesting that corresponding residues in insect $\mathrm{nAChRs}$ may play important roles in determining neonicotinoid sensitivity. Ser186 in loop C was found to form hydrogen bonds with Gln163 as well as Tyr164 in loop $\mathrm{F}$, suggesting that these hydrogen bondable residues can also indirectly influence the selective interactions with neonicotinoids. CTD forms hydrogen bond with the backbone carbonyl of Trp143 in loop B and shows weaker hydrophobic contacts with Trp143 compared with other neonicotinoids tested, which may altogether lead to its unique actions on nAChRs. Although there are sequence and structural similarities between AChBPs and nAChRs, there are also important differences. Future structural studies on AChBP mutants engineered to resemble more closely insect or human nAChRs could help to enhance even further our understanding of neonicotinoid actions and selectivity. Nevertheless, we have provided new insights into the molecular basis of differential actions of neonicotinoid molecules. These results may be of value in the design of even safer new crop protection agents.

Acknowledgments The authors thank Dr. Takaaki Hikima and Dr. Tetsuya Shimizu for help on data collection at BL44B2, Ms. Naoko Takahashi for $\mathrm{N}$-terminal sequencing and mass spectrometry and Dr Atsuo Miyazawa for advices on the secondary structure assignment. KM was supported in part by the "Academic Frontier" Project for Private Universities from the Ministry of Education, Culture, Sports, Science and Technology, and by the Integrated Research Project for Plant, Insect and Animal using Genome Technology from the Ministry of Agriculture, Forestry and Fisheries of Japan. DBS was supported by The Medical Research Council of the UK.

Open Access This article is distributed under the terms of the Creative Commons Attribution Noncommercial License which permits any noncommercial use, distribution, and reproduction in any medium, provided the original author(s) and source are credited.

\section{References}

Adachi S, Oguchi T, Tanida H, Park S-Y, Shimizu H, Miyatake H, Kamiya N, Shiro Y, Inoue Y, Ueki T, Iizuka T (2001) The RIKEN structural biology beamline II (BL44B2) at the SPring-8. Nucl Instrum Methods Phys Res A467/A468:711-714

Aridon P, Marini C, Di Resta C, Brilli E, De Fusco M, Politi F, Parrini E, Manfredi I, Pisano T, Pruna D, Curia G, Cianchetti C, Pasqualetti M, Becchetti A, Guerrini R, Casari G (2006) Increased sensitivity of the neuronal nicotinic receptor $\alpha 2$ subunit causes familial epilepsy with nocturnal wandering and ictal fear. Am J Hum Genet 79:342-350

Arneric SP, Holladay M, Williams M (2007) Neuronal nicotinic receptors: a perspective on two decades of drug discovery research. Biochem Pharmacol 74:1092-1101
Bourne Y, Talley TT, Hansen SB, Taylor P, Marchot P (2005) Crystal structure of a $\mathrm{Cbtx}-\mathrm{AChBP}$ complex reveals essential interactions between snake $\alpha$-neurotoxins and nicotinic receptors. EMBO J 24:1512-1522

Brejc K, van Dijk WJ, Klaassen RV, Schuurmans M, van Der Oost J, Smit AB, Sixma TK (2001) Crystal structure of an ACh-binding protein reveals the ligand-binding domain of nicotinic receptors. Nature 411:269-276

Brown LA, Ihara M, Buckingham SD, Matsuda K, Sattelle DB (2006) Neonicotinoid insecticides display partial and super agonist actions on native insect nicotinic acetylcholine receptors. J Neurochem 99:608-615

Brünger AT, Adams PD, Clore GM, DeLano WL, Gros P, GrosseKunstleve RW, Jiang JS, Kuszewski J, Nilges M, Pannu NS, Read RJ, Rice LM, Simonson T, Warren GL (1998) Crystallography \& NMR system: a new software suite for macromolecular structure determination. Acta Crystallogr D Biol Crystallogr 54:905-921

Cashin AL, Petersson EJ, Lester HA, Dougherty DA (2005) Using physical chemistry to differentiate nicotinic from cholinergic agonists at the nicotinic acetylcholine receptor. J Am Chem Soc 127:350-356

Celie PH, van Rossum-Fikkert SE, van Dijk WJ, Brejc K, Smit AB, Sixma TK (2004) Nicotine and carbamylcholine binding to nicotinic acetylcholine receptors as studied in AChBP crystal structures. Neuron 41:907-914

Celie PH, Kasheverov IE, Mordvintsev DY, Hogg RC, van Nierop P, van Elk R, van Rossum-Fikkert SE, Zhmak MN, Bertrand D, Tsetlin V, Sixma TK, Smit AB (2005) Crystal structure of nicotinic acetylcholine receptor homolog AChBP in complex with an $\alpha$-conotoxin PnIA variant. Nat Struct Mol Biol 12:582588

Corringer PJ, Le Novere N, Changeux JP (2000) Nicotinic receptors at the amino acid level. Annu Rev Pharmacol Toxicol 40:431458

Court J, Martin-Ruiz C, Piggott M, Spurden D, Griffiths M, Perry E (2001) Nicotinic receptor abnormalities in Alzheimer's disease. Biol Psychiatry 49:175-184

Couturier S, Bertrand D, Matter JM, Hernandez MC, Bertrand S, Millar N, Valera S, Barkas T, Ballivet M (1990) A neuronal nicotinic acetylcholine receptor subunit $\alpha 7$ is developmentally regulated and forms a homo-oligomeric channel blocked by $\alpha$-BTX. Neuron 5:847-856

Dani JA, Bertrand D (2007) Nicotinic acetylcholine receptors and nicotinic cholinergic mechanisms of the central nervous system. Annu Rev Pharmacol Toxicol 47:699-729

Deglise P, Grünewald B, Gauthier M (2002) The insecticide imidacloprid is a partial agonist of the nicotinic receptor of honeybee Kenyon cells. Neurosci Lett 321:13-16

Dutertre S, Ulens C, Büttner R, Fish A, van Elk R, Kendel Y, Hopping G, Alewood PF, Schroeder C, Nicke A, Smit AB, Sixma TK, Lewis RJ (2007) AChBP-targeted a $\alpha$-conotoxin correlates distinct binding orientations with nAChR subtype selectivity. EMBO J 26:3858-3867

Elgoyhen AB, Johnson DS, Boulter J, Vetter DE, Heinemann S (1994) $\alpha 9$ : an acetylcholine receptor with novel pharmacological properties expressed in rat cochlear hair cells. Cell 79:705-715

Elgoyhen AB, Vetter DE, Katz E, Rothlin CV, Heinemann SF, Boulter J (2001) $\alpha 10$ : a determinant of nicotinic cholinergic receptor function in mammalian vestibular and cochlear mechanosensory hair cells. Proc Natl Acad Sci USA 98:3501-3506

Emsley P, Cowtan K (2004) Coot: model-building tools for molecular graphics. Acta Crystallogr D Biol Crystallogr 60:2126-2132

Engel AG, Ohno K, Sine SM (2003) Sleuthing molecular targets for neurological diseases at the neuromuscular junction. Nat Rev Neurosci 4:339-352 
Esnouf RM (1999) Further additions to MolScript version 1.4, including reading and contouring of electron-density maps. Acta Crystallogr D Biol Crystallogr 55:938-940

Gerzanich V, Anand R, Lindstrom J (1994) Homomers of $\alpha 8$ and $\alpha 7$ subunits of nicotinic receptors exhibit similar channel but contrasting binding site properties. Mol Pharmacol 45:212-220

Hansen SB, Taylor P (2007) Galanthamine and non-competitive inhibitor binding to ACh-binding protein: evidence for a binding site on non- $\alpha$-subunit interfaces of heteromeric neuronal nicotinic receptors. J Mol Biol 369:895-901

Hansen SB, Sulzenbacher G, Huxford T, Marchot P, Taylor P, Bourne Y (2005) Structures of Aplysia AChBP complexes with nicotinic agonists and antagonists reveal distinctive binding interfaces and conformations. EMBO J 24:3635-3646

Ihara M, Matsuda K, Otake M, Kuwamura M, Shimomura M, Komai K, Akamatsu M, Raymond V, Sattelle DB (2003) Diverse actions of neonicotinoids on chicken $\alpha 7, \alpha 4 \beta 2$ and Drosophilachicken $\operatorname{SAD} \beta 2$ and $\operatorname{ALS} \beta 2$ hybrid nicotinic acetylcholine receptors expressed in Xenopus laevis oocytes. Neuropharmacology 45:133-144

Ihara M, Matsuda K, Shimomura M, Sattelle D, Komai K (2004) Super agonist actions of clothianidin and related compounds on the $\mathrm{SAD} \beta 2$ nicotinic acetylcholine receptor expressed in Xenopus laevis oocytes. Biosci Biotechnol Biochem 68:761-763

Ihara M, Brown LA, Ishida C, Okuda H, Sattelle DB, Matsuda K (2006) Actions of imidacloprid, clothianidin and related neonicotinoids on nicotinic acetylcholine receptors of American cockroach neurons and their relationships with insecticidal potency. J Pestic Sci 31:35-40

Ihara M, Hirata K, Ishida C, Kagabu S, Matsuda K (2007a) Blocking actions of alkylene-tethered bis-neonicotinoids on nicotinic acetylcholine receptors expressed by terminal abdominal ganglion neurons of Periplaneta americana. Neurosci Lett 425:137140

Ihara M, Shimomura M, Ishida C, Nishiwaki H, Akamatsu M, Sattelle DB, Matsuda K (2007b) A hypothesis to account for the selective and diverse actions of neonicotinoid insecticides at their molecular targets, nicotinic acetylcholine receptors: catch and release in hydrogen bond networks. Invert Neurosci $7: 47-51$

Karlin A (2002) Emerging structure of the nicotinic acetylcholine receptors. Nat Rev Neurosci 3:102-114

Larkin MA, Blackshields G, Brown NP, Chenna R, McGettigan PA, McWilliam H, Valentin F, Wallace IM, Wilm A, Lopez R, Thompson JD, Gibson TJ, Higgins DG (2007) Clustal W and Clustal X version 2.0. Bioinformatics 23:2947-2948

Leslie AGW (1992) Recent changes to the MOSFLM package for processing film and image plate data. Joint CCP4+ESF-EAMCB Newslett Prot Crystallogr 26

Lindstrom JM (2003) Nicotinic acetylcholine receptors of muscles and nerves: comparison of their structures, functional roles, and vulnerability to pathology. Ann N Y Acad Sci 998:41-52

Maienfisch P, Huerlimann H, Haettenschwiler J (2000) A novel method for the preparation of $N, N$ '-disubstituted- $N$ ' '-nitroguanidines, including a practical synthesis of the neonicotinoid insecticide clothianidin. Tetrahedron Lett 41:7187-7191

Marutle A, Warpman U, Bogdanovic N, Lannfelt L, Nordberg A (1999) Neuronal nicotinic receptor deficits in Alzheimer patients with the Swedish amyloid precursor protein 670/671 mutation. J Neurochem 72:1161-1169

Matsuda K, Buckingham SD, Kleier D, Rauh JJ, Grauso M, Sattelle DB (2001) Neonicotinoids: insecticides acting on insect nicotinic acetylcholine receptors. Trends Pharmacol Sci 22:573-580

Matsuda K, Shimomura M, Ihara M, Akamatsu M, Sattelle DB (2005) Neonicotinoids show selective and diverse actions on their nicotinic receptor targets: electrophysiology, molecular biology, and receptor modeling studies. Biosci Biotechnol Biochem 69:1442-1452

McCoy AJ (2007) Solving structures of protein complexes by molecular replacement with Phaser. Acta Crystallogr D Biol Crystallogr 63:32-41

Merritt EA, Bacon DJ (1997) Raster3D: Photorealistic molecular graphics. Macromol Crystallogr Pt B 277:505-524

Millar NS, Denholm I (2007) Nicotinic acetylcholine receptors: targets for commercially important insecticides. Invert Neurosci 7:53-66

Miyazawa A, Fujiyoshi Y, Unwin N (2003) Structure and gating mechanism of the acetylcholine receptor pore. Nature 423:949955

Morgan NV, Brueton LA, Cox P, Greally MT, Tolmie J, Pasha S, Aligianis IA, van Bokhoven H, Marton T, Al-Gazali L, Morton JE, Oley C, Johnson CA, Trembath RC, Brunner HG, Maher ER (2006) Mutations in the embryonal subunit of the acetylcholine receptor (CHRNG) cause lethal and Escobar variants of multiple pterygium syndrome. Am J Hum Genet 79:390-395

Narahashi T (2000) Neuroreceptors and ion channels as the basis for drug action: past, present, and future. J Pharmacol Exp Ther 294:1-26

Nishiwaki H, Nakagawa Y, Takeda D, Okazawa A, Akamatsu M, Miyagawa H, Ueno T, Nishimura K (2000) Binding activity of substituted benzyl derivatives of chloronicotinyl insecticides to housefly-head membranes, and its relationship to insecticidal activity against the housefly Musca domestica. Pest Manag Sci $56: 875-881$

Otwinowski Z, Minor W (1997) Processing of X-ray diffraction data collected in oscillation mode. Methods Enzymol 276:307-326

Raymond-Delpech V, Matsuda K, Sattelle BM, Rauh JJ, Sattelle DB (2005) Ion channels: molecular targets of neuroactive insecticides. Invert Neurosci 5:119-133

Salgado VL, Saar R (2004) Desensitizing and non-desensitizing subtypes of $\alpha$-bungarotoxin-sensitive nicotinic acetylcholine receptors in cockroach neurons. J Insect Physiol 50:867-879

Sattelle DB (1980) Acetylcholine receptors of insects. Adv Insect Physiol 15:215-315

Shimomura M, Okuda H, Matsuda K, Komai K, Akamatsu M, Sattelle DB (2002) Effects of mutations of a glutamine residue in loop $\mathrm{D}$ of the $\alpha 7$ nicotinic acetylcholine receptor on agonist profiles for neonicotinoid insecticides and related ligands. Br J Pharmacol 137:162-169

Shimomura M, Yokota M, Okumura M, Matsuda K, Akamatsu M, Sattelle DB, Komai K (2003) Combinatorial mutations in loops $\mathrm{D}$ and $\mathrm{F}$ strongly influence responses of the $\alpha 7$ nicotinic acetylcholine receptor to imidacloprid. Brain Res 991:71-77

Shimomura M, Yokota M, Matsuda K, Sattelle DB, Komai K (2004) Roles of loop $\mathrm{C}$ and the loop B-C interval of the nicotinic receptor $\alpha$ subunit in its selective interactions with imidacloprid in insects. Neurosci Lett 363:195-198

Shimomura M, Satoh H, Yokota M, Ihara M, Matsuda K, Sattelle DB (2005) Insect-vertebrate chimeric nicotinic acetylcholine receptors identify a region, loop B to the N-terminus of the Drosophila $\mathrm{D} \alpha 2$ subunit, which contributes to neonicotinoid sensitivity. Neurosci Lett 385:168-172

Shimomura M, Yokota M, Ihara M, Akamatsu M, Sattelle DB, Matsuda K (2006) Role in the selectivity of neonicotinoids of insect-specific basic residues in loop $\mathrm{D}$ of the nicotinic acetylcholine receptor agonist binding site. Mol Pharmacol 70:1255-1263

Sine SM, Engel AG (2006) Recent advances in Cys-loop receptor structure and function. Nature 440:448-455

Smit AB, Syed NI, Schaap D, van Minnen J, Klumperman J, Kits KS, Lodder H, van der Schors RC, van Elk R, Sorgedrager B, Brejc K, Sixma TK, Geraerts WP (2001) A glia-derived acetylcholine- 
binding protein that modulates synaptic transmission. Nature 411:261-268

Steinlein OK (2004) Genetic mechanisms that underlie epilepsy. Nat Rev Neurosci 5:400-408

Tan J, Galligan JJ, Hollingworth RM (2007) Agonist actions of neonicotinoids on nicotinic acetylcholine receptors expressed by cockroach neurons. Neurotoxicology 28:829-842

Tomizawa M, Casida JE (2005) Neonicotinoid insecticide toxicology: mechanisms of selective action. Annu Rev Pharmacol Toxicol 45:247-268

Tomizawa M, Talley TT, Maltby D, Durkin KA, Medzihradszky KF, Burlingame AL, Taylor P, Casida JE (2007) Mapping the elusive neonicotinoid binding site. Proc Natl Acad Sci USA 104:90759080

Tomizawa M, Maltby D, Talley TT, Durkin KA, Medzihradszky KF, Burlingame AL, Taylor P, Casida JE (2008) Atypical nicotinic agonist bound conformations conferring subtype selectivity. Proc Natl Acad Sci USA 105:1728-1732f

Ulens C, Hogg RC, Celie PH, Bertrand D, Tsetlin V, Smit AB, Sixma TK (2006) Structural determinants of selective $\alpha$-conotoxin binding to a nicotinic acetylcholine receptor homolog AChBP. Proc Natl Acad Sci USA 103:3615-3620

Unwin N (2005) Refined structure of the nicotinic acetylcholine receptor at $4 \AA$ resolution. J Mol Biol 346:967-989

Woodruff-Pak DS, Gould TJ (2002) Neuronal nicotinic acetylcholine receptors: involvement in Alzheimer's disease and schizophrenia. Behav Cogn Neurosci Rev 1:5-20

Yoshimura M, Yamashita E, Suzuki M, Yamamoto M, Yoshikawa S, Tsukihara T, Nakagawa A (2007) Synchrotoron radiation instrumentation. In: Synchrotron radiation instrumentation: 9th international conference, vol 879, pp 1916-1919 